\title{
IDENTIFIKASI PERMUKIMAN KUMUH DI KELURAHAN TALUMOLO KECAMATAN DUMBO RAYA KOTA GORONTALO Identification of Slum Settlement in Kelurahan Talumolo Kecamatan Dumbo Raya Kota Gorontalo
}

\author{
Muhammad Rijal Syukri ${ }^{1}$, Sri Sutarni Arifin ${ }^{2}$ \\ ${ }^{1,2}$ Teknik Arsitektur Universitas Negeri Gorontalo, Indonesia \\ Email Korespondensi: muh.rijalsyukri@gmail.com
}

DOI: http://dx.doi.org/10.31314/jsig.v1i1.144

\begin{abstract}
The high number of urban residents due to the large number of migrants caused the reduction of land for settlements. This triggered the emergence of slums in various areas of the city. Dumbo Raya sub-district is a coastal area that is geographically flanked by the sea and hills. This condition causes the region to be very vulnerable to the disaster so that the growth of irregular or well-structured settlements will increase the chances of disaster occurring. This study aims to determine the slums in Talumolo Subdistrict, Dumbo Raya District based on several indicators that have been determined and obtain data in the form of the area of slum identified. This study also aims to determine the level of slum in the selected area. The method used in this research is through the application of Geographic Information System (GIS) and data analysis of questionnaires through mathematical calculations. Through this study obtained results in the form of: 1) Determination of locations included in the slum area based on 6 (six) variables namely non-economic vitality, economic vitality, land status, condition of infrastructure facilities, commitment of local governments and priority handling; 2) The results of identification and delineation of slum areas in Talumolo Village indicate that there is a slum area of 32,235 hectares with MEDIUM classification.
\end{abstract}

Keywords: region, settlement, slum, Gorontalo, urban

\begin{abstract}
Abstrak - Tingginya jumlah penduduk kota akibat banyaknya pendatang menyebabkan berkurangnya lahan untuk permukiman. Hal ini memicu munculnya permukiman kumuh pada berbagai wilayah kota. Kecamatan Dumbo Raya merupakan wilayah pesisir yang secara geografis wilayahnya diapit oleh laut dan perbukitan. Kondisi ini mengakibatkan wilayah ini sangat rawan dengan bencana sehingga pertumbuhan permukiman yang tidak teratur atau tertata dengan baik akan memperbesar peluang terjadinya bencana. Penelitian ini bertujuan untuk menentukan kawasan kumuh yang ada di Kelurahan Talumolo Kecamatan Dumbo Raya berdasarkan beberapa indikator yang telah ditetapkan dan memperoleh data berupa luas kawasan kumuh yang diidentifikasi. Penelitian ini juga bertujuan untuk menentukan tingkat kekumuhannya kawasan yang terpilih. Metode yang digunakan pada penelitian ini adalah melalui aplikasi Sistem Informasi Geografis (SIG) dan analisis data hasil kuisioner melalui hitungan matematis. Melalui penelitian ini diperoleh hasil berupa : 1) Penentuan lokasi yang termasuk ke dalam kawasan kumuh disusun berdasarkan 6 (enam) variabel yaitu vitalitas non ekonomi, vitalitas ekonomi, status tanah, kondisi prasarana sarana, komitmen pemerintah daerah dan prioritas penanganan; 2) Hasil identifikasi dan deliniasi kawasan permukiman kumuh di Kelurahan Talumolo menunjukkan bahwa terdapat kawasan kumuh seluas 32,235 hektar dengan tingkat kekumuhan SEDANG.
\end{abstract}

Kata kunci: kawasan, permukiman, kumuh, Gorontalo, perkotaan 


\section{PENDAHULUAN}

Berdasarkan sejarah kota, masalah perumahan belum pernah tuntas bahkan terus bertambah. Pengalaman berbagai kota tua di zaman dahulu dan kota modern sekarang ini telah menunjukkan bahwa masalah perumahan adalah masalah yang tidak pernah selesai. Berbagai masalah dan kendala perumahan bertabrakan karena adanya tuntutan peningkatan mutu bagi orang yang berpunya dan kebutuhan akan sekedar papan atau tempat bernaung bagi penduduk kota yang miskin dan pendatang baru. Tingginya jumlah penduduk kota akibat banyaknya pendatang menyebabkan berkurangnya lahan untuk permukiman. Hal ini memicu munculnya permukiman kumuh pada berbagai wilayah kota.

Pembangunan permukiman saat ini kurang atau belum mengantisipasi dan mengakomodir perkembangan kawasan perkotaan. Hal ini akan menimbulkan beberapa implikasi permasalahan antara lain: (a) tidak meratanya penyediaan infrastruktur perkotaan, dan (b) tidak tersedianya lingkungan permukiman yang layak, (c) tidak terkendalinya pembangunan permukiman pada daerah-daerah non-permukiman, dan (d) terjadinya permukiman kumuh.

Kompleksitas kegiatan kawasan kumuh perkotaan akan terus berkembang dari waktu ke waktu dan meliputi semua lini di perkotaan, perkembangan kawasan perkotaan ini akan menjadi daya tarik tersendiri bagi masyarakat untuk berdomisili dan melakukan aktivitas ekonominya di perkotaan. Kelurahan Talumolo Kecamatan Dumbo Raya merupakan wilayah pesisir yang secara geografis wilayahnya diapit oleh laut dan perbukitan. Kondisi ini mengakibatkan wilayah ini sangat rawan dengan bencana sehingga pertumbuhan permukiman yang tidak teratur atau tertata dengan baik akan memperbesar peluang terjadinya bencana. Oleh karena itu, disusun penelitian ini yang berjudul "Identifikasi Permukiman Kumuh di Kecamatan Dumbo Raya Kota Gorontalo" yang bertujuan untuk menentukan kawasan yang terindikasi sebagai kawasan kumuh sehingga memudahkan dalam proses perencanaan penataan permukiman kumuh.

Penelitian ini bertujuan untuk menentukan kawasan kumuh yang ada di Kecamatan Dumbo Raya berdasarkan beberapa indikator yang telah ditetapkan dan memperoleh data berupa luas kawasan kumuh yang diidentifikasi. Penelitian ini juga bertujuan untuk menentukan tingkat kekumuhannya kawasan yang terpilih. Melalui penelitian ini akan diperoleh data yang akan menjadi dasar dalam penyusunan program penataan permukiman kumuh di Kota Gorontalo. Data yang diperoleh dari penelitian ini diharapkan dapat menjadi acuan bagi pemerintah baik Nasional maupun Daerah dalam perencanaan proses pembangunan di wilayah kajian.

\section{METODE DAN DATA} berikut :

Metode yang digunakan adalah penelitian deskriptif kuantitatif melalui tahapan sebagai

1. Tahapan pengumpulan data meliputi studi literatur, pengumpulan data primer, peta-peta dasar.

2. Survey untuk menentukan bentuk dan tingkat kekumuhan kawasan melalui identifikasi sarana dan prasarana permukiman yang tersedia serta gambaran kondisinya.

3. Penyebaran dan pengisian kuisioner oleh masyarakat untuk mengidentifikasi kondisi sosial ekonomi masyarakat pada wilayah penelitian.

4. Analisis data hasil survey melalui Sistem Informasi Geografis

Data hasil survey lapangan selanjutnya dihitung menggunakan rumus matematika untuk memperoleh persentasi ketidakteraturan bangunan, tingkat kepadatan bangunan, ketidaksesuaian bangunan yang ada dengan persyaratan teknis bangunan, cakupan pelayanan jalan lingkungan, kualitas permukaan jalan lingkungan, ketersediaan akses aman air minum, ketidakmampuan megalirkan limpasan air, ketersediaan drainase, sistem pemeliharaan drainase, keterhubungan drainase dengan sistem perkotaan, sistem pengelolaan limbah berdasarkan standar teknis, prasarana dan sarana air limbah yang sesuai dengan standar teknis, sistem pengelolaan prasarana dan sarana persampahan, ketersediaan prasarana dan sarana proteksi kebakaran dan kesesuaian dengan dokumen perencanaan.

\section{HASIL DAN PEMBAHASAN}

Hasil delineasi kawasan kumuh ditetapkan berdasarkan hasil identifikasi kondisi fisik permukiman yang mengacu pada kriteria penentuan kawasan permukiman kumuh untuk berupa: 
1. Vitalitas Non Ekonomi

a. Kesesuaian dengan tata ruang

b. Kondisi fisik bangunan (pertambahan bangunan liar, kepadatan bangunan, bangunan temporer, building coverage, jarak antar bangunan)

c. Kondisi kependudukan (kepadatan penduduk, pertumbuhan penduduk)

2. Vitalitas Ekonomi
a. Letak strategis kawasan
b. Jarak ke tempat mata pencaharian
c. Fungsi kawasan sekitar

3. Status Tanah

a. Dominasi status tanah

b. Status kepemilikan tanah

4. Kondisi Sarana Prasarana
a. Kondisi jalan lingkungan
b. Kondisi drainase
c. Kondisi Air Minum
d. Kondisi Air Limbah
e. Kondisi Persampahan

Hasil identifikasi dan deliniasi kawasan permukiman kumuh di Kota Gorontalo Tahun 2016 sebanyak 6 lokasi kawasan kumuh dengan luas kawasan kumuh sekitar 62,232 Ha. Kawasan permukiman kumuh tersebut tersebar di Kecamatan Dumbo Raya meliputi Kelurahan Talumolo, Kelurahan Leato Utara, dan Kelurahan Leato Selatan. Kawasan permukiman kumuh di Kelurahan Talumolo seluas 32,235 hektar dengan karakteristik tipologi di pinggir pantai, mata pencaharian mayoritas penduduk yaitu nelayan dan pekerja pelabuhan, kepadatan bangunan tinggi hingga sangat tinggi. Secara rinci lokasi kawasan permukiman kumuh di wilayah Kota Gorontalo disajikan pada Gambar 1. Permasalahan lingkungan pada lokasi kawasan permukiman kumuh di wilayah tersebut meliputi :

1) Kepadatan bangunan tinggi dan kualitas bangunan yang tidak memenuhi syarat;

2) Kondisi jalan lingkungan yang belum diperkeras dan rusak;

3) Permasalahan akses terhadap air minum dengan kualitas baik;

4) Permasalahan drainase air yang belum tersedia dan belum memenuhi persyaratan teknis;

5) Belum tersedianya sarana pengelolaan air limbah yang sesuai persyaratan teknis;

6) Belum tersedianya fasilitas sanitasi masyarakat (MCK) yang sesuai persyaratan teknis;

7) Belum tersedianya sarana pengelolaan persampahan yang sesuai persyaratan teknis;

\section{Hasil Identifikasi Kawasan Permukiman Kumuh}

Kelurahan Talumolo Kecamatan Dumbo Raya Kota Gorontalo pada tahun 2016 terdiri atas 5.647 jiwa dengan $1.538 \mathrm{KK}$. Tipologi kawasan merupakan daerah tepi air/pantai yang diapit oleh daerah perbukitan. Hasil identifikasi kawasan menunjukkan bahwa terdapat permasalahan seperti jalan lingkungan yang pada umumnya belum diperkeras atau masih berupa jalan tanah dan tidak dilengkapi dengan drainase. Belum tersedia sistem penanganan maupun pengolahan limbah sehingga limbah domestik terbuang ke saluran drainase maupun tanah terbuka. Selain itu, prasarana persampahan tidak tersedia baik dalam bentuk bak sampah, pembuangan sampah sementara maupun sistem pengelolaan sampah lainnya. Hasil analisis penilaian tingkat kekumuhan kawasan berdasarkan 7 indikator kawasan kumuh yang termuat pada Peraturan Menteri Pekerjaan Umum dan Perumahan Rakyat No. 2/PRT/M/2016 di Keluraha Talumolo dapat dilihat pada Tabel 1. 


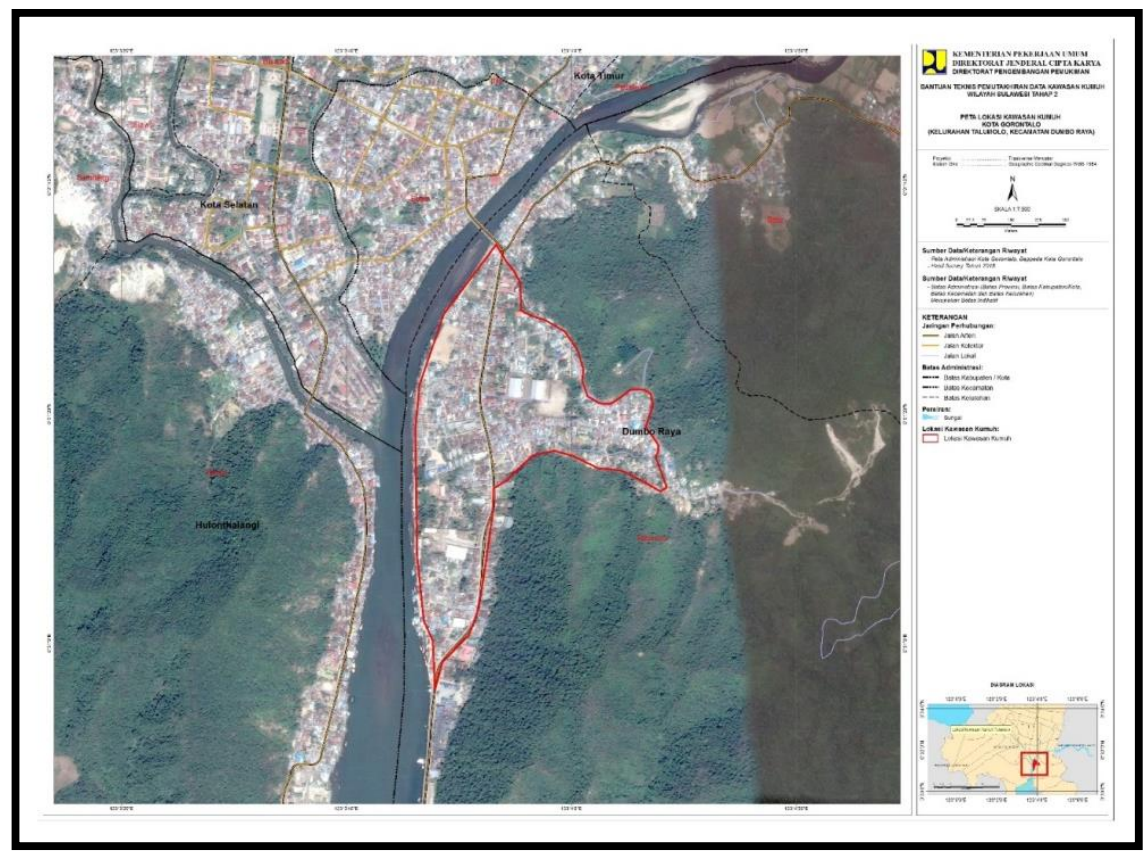

Gambar 1. Hasil Delineasi Kawasan Permukiman Kumuh di Kelurahan Talumolo Kec. Dumbo Raya Kota Gorontalo

Tabel 1. Kriteria dan Indikator Penilaian Tingkat Kekumuhan Kawasan

\begin{tabular}{|c|c|c|}
\hline Aspek & Kriteria dan Indikator & Parameter \\
\hline Kondisi & a. Ketidakteraturan Bangunan & $51 \%-75 \%$ bangunan pada lokasi tidak memiliki keteraturan. \\
\hline Bangunan & $\begin{array}{l}\text { b. Tingkat Kepadatan Bangunan } \\
\text { c. Kualitas Bangunan }\end{array}$ & $\begin{array}{l}51 \%-75 \% \text { kepadatan bangunan pada lokasi tidak sesuai } \\
\text { ketentuan } \\
76 \% \text { - } 100 \% \text { bangunan pada lokasi tidak memenuhi persyaratan } \\
\text { teknis. }\end{array}$ \\
\hline Kondisi Jalan & a. Cakupan Jaringan Pelayanan & $76 \%-100 \%$ area tidak terlayani oleh jaringan jalan lingkungan. \\
\hline Kondisi Drair & a. Ketidaktersediaan Drainase & $25 \%-50 \%$ area tidak tersedia drainase lingkungan. \\
\hline Lingkungan & $\begin{array}{l}\text { b. Pemeliharaan Drainase } \\
\text { c. Ketidakterhubungan dengan Sistem } \\
\text { Drainase Perkotaan } \\
\text { d. Kualitas Konstruksi Drainase }\end{array}$ & $\begin{array}{l}\text { : } 76 \%-100 \% \text { area memiliki drainase lingkungan yang kotor dan } \\
\text { berbau. } \\
76 \%-100 \% \text { drainase lingkungan tidak terhubung dengan hirarki } \\
\text { di atasnya. } \\
76 \%-100 \% \text { area memiliki kualitas konstruksi drainase } \\
\text { lingkungan buruk. }\end{array}$ \\
\hline $\begin{array}{l}\text { Kondisi } \\
\text { Pengelolaan Air }\end{array}$ & a. Sistem Pengelolaan Air Limbah & $\begin{array}{l}: \quad 25 \%-50 \% \text { area memiliki sistem pengelolaan air limbah yang } \\
\text { tidak sesuai standar teknis. }\end{array}$ \\
\hline Limbah & b. Prasarana dan Sarana Air Limbah & $\begin{array}{l}\text { : } 25 \%-50 \% \text { area memiliki prasarana dan sarana pengelolaan air } \\
\text { limbah yang tidak memenuhi persyaratan teknis. }\end{array}$ \\
\hline $\begin{array}{l}\text { Kondisi } \\
\text { Pengelolaan }\end{array}$ & a. Prasarana dan Sarana Persampahan & $\begin{array}{l}76 \%-100 \% \text { area memiliki prasarana dan sarana pengelolaan } \\
\text { persampahan tidak memenuhi persyaratan teknis. }\end{array}$ \\
\hline Persampahan & b. Sistem Pengelolaan Persampahan & $\begin{array}{l}: \quad 76 \%-100 \% \text { area memiliki sistem pengelolaan persampahan yang } \\
\text { tidak sesuai standar teknis. }\end{array}$ \\
\hline & $\begin{array}{l}\text { c. Pemeliharaan Sarana Prasarana } \\
\text { Pengelolaan Persampahan }\end{array}$ & $\begin{array}{l}\text { : } 76 \%-100 \% \text { area memiliki sarana prasarana persampahan yang } \\
\text { tidak terpelihara. }\end{array}$ \\
\hline
\end{tabular}

(Sumber : Data Primer, 2016)

Berdasarkan hasil perhitungan menggunakan rumus matematis data primer yang ada pada lokasi penelitian, maka diperoleh hasil yaitu nilai kekumuhan kawasan di Kelurahan Talumolo Kecamatan Dumbo Raya Kota Gorontalo adalah sebesar 46. Tingkat kekumuhan ini berada pada klasifikasi SEDANG yaitu 45 - 70 (Kumuh Sedang). 


\section{KESIMPULAN}

Berdasarkan hasil penelitian Identifikasi Kawasan Permukiman Kumuh di Kelurahan Talumolo Kecamatan Dumbo Raya Kota Gorontalo, maka dapat disimpulkan sebagai berikut :

1. Penentuan lokasi yang termasuk ke dalam kawasan kumuh disusun berdasarkan 6 (enam) variabel yaitu vitalitas non ekonomi, vitalitas ekonomi, status tanah, kondisi prasarana sarana, komitmen pemerintah daerah dan prioritas penanganan.

2. Perhitungan tingkat kekumuhan kawasan didasarkan pada 7 aspek yaitu : Kondisi Bangunan, Kondisi Jalan Lingkungan, Kondisi Penyediaan Air Minum, Kondisi Drainase Lingkungan, Kondisi Pengelolaan Air Limbah, Kondisi Pengelolaan Persampahan, Kondisi Proteksi Kebakaran.

Kawasan permukiman kumuh di Kelurahan Talumolo seluas 32,235 hektar; Kelurahan Leato Utara seluas 13,48 hektar; dan Kelurahan Leato Selatan seluas 16,517 hektar dengan tingkat kekumuhan SEDANG.

\section{DAFTAR PUSTAKA}

Badan Pusat Statistik Kota Gorontalo, 2016. Kecamatan Dumbo Raya Dalam Angka, 2015.

Burhanuddin, 1998. Partisipasi Masyarakat Dalam Program Perbaikan Lingkungan Perkotaan. Tesis Mahasiswa Pascasarjana Universitas Hasanuddin, Makassar.

Sinulingga, Budi, 1999. Pembangunan Kota Tinjauan Regional dan Lokal. Pustaka Sinar Harapan, Jakarta.

Undang-undang RI Nomor 4 Tahun 1992 tentang Perumahan dan Pemukiman. Jakarta : Departemen Kesehatan RI.

Undang-undang No. 1 Tahun 2011 tentang Perumahan dan Kawasan Permukiman.

Yudohusodo, Siswono. 1991. Rumah Untuk Seluruh Rakyat. Direktorat Jendral Cipta Karya: Jakarta. 